manner the practically instantaneous sterilisation of each stool the moment it left the bedpan was secured day or night. As far as nuisance from the fumes was concerned, there was practically no smell. The vapour had a heavy odour redolent of carbolic acid when the lid of the pot was removed. At one or two yards' distance it was scarcely perceptible. There was no difficulty in persuading the attendants to keep the fire lighted, as they seemed to think this very little trouble.

The bedpans were invariably emptied into the boiling cauldron, whose wide mouth was extremely well adapted for the purpose.

In addition to the stools from enteric cases, all stools and urine from patients confined to bed were emptied into it, and also sweepings from the wards. The apparatus has been in use for nearly two months, and over 200 cases of enteric fever have been under treatment.

No case of enteric fever has occurred among the orderlies employed in nursing and for pioneer work. The average strength has been about 35 .

Dr. Turner, Medical Officer of Health in South Africa, expressed himself very favourably on the process, and arranged for the perfecting of detail. At present we have two large iron boilers arranged side by side, with furnaces underneath one is used for excreta, etc., and the other for infected bedclothes or other articles requiring disinfection.

The simplicity and cleanliness of the process render it one which might be adopted with benefit in any hospital, and the cost of maintenance is very small. The fact that after having zndergone the process the sterilised excreta can be passed into drains without risk of spreading infecrion is most important, as they can be disposed of by whatever system is in use for healthy dejections.

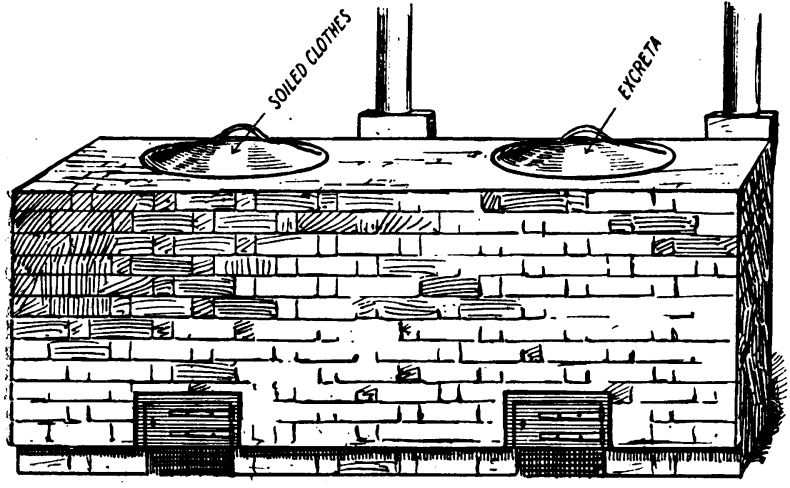

Brick furnaces.

By the courtesy of Dr. Turner, Civil Surgeon A. M. Dodd, formerly House-Surgeon of the Royal Southern Hospital, Liverpool, and now attached to this hospital for duty, has been enabled to make a bacteriological examination of the contents of the cauldron as follows :

A control experiment was made by inoculating one nutrient agar tube from the contents of a bedpan which the attendant was about to empty into the cauldron. The stool was poured into the cauldron and ten minutes after five nutrient agar tubes were inoculated from the contents of the pot. All the tubes were incubated at blood heat for twenty-four hours. while the five infected by the contents of the pot showed no sign of bacterial growth.

I may mention that the temperature of the contents of the cauldron varied from $95^{\circ} \mathrm{C}$. to $97^{\circ} \mathrm{C}$. This is accounted for by the elevation of Pretoria, which is over 4,000 feet above the sea level.

Dr. Dodd is making further bacteriological investigations on this subject in order to demonstrate the completeness and rapidity of the process in destroying the vitality of organisms so dangerous to human life and so liable to become disseminated by dust and flies in a country like Africa. He hopes to communicate the result a little later. This process is, I believe, about to be introduced into other hospitals in Pretoria.

According to the Philadelphia Medical Journal, the Board of Education in that city is about to undertake to train school children in ambidexterity through a regular course of exercises to be carried out in the schools.

\section{THE TREATMENT OF DYSENTERY.}

BY WILFRED WATKINS-PITCHFORD, M.B.LOND.,

$$
\text { F.R.C.S.EnG., }
$$

C.M.O. with No. 7 General Hospital, South Africa Field Force, Estcourt, Natal.

DURING the later months of last summer (January to April) cases of severe dysentery were very numerous on this side (Natal), and I think that nearly every known method of treatment was resorted to in this hospital. In speaking of "dysentery," I do not wish to confine myself to any one of the varieties of colitis which come under that comprehensive and expressive denomination. Diversity of pathology has not, I believe, so far, called for any serious variations in treatment.

Saline Aperients.-As in other " general hospitals," our cases have been almost all handed over to us from either field or stationary hospitals nearer the front. For this reason we have had little opportunity of treating dysentery in its initlal stages, and it is probably on this account that the treatment by saline aperients, sodium or magnesium sulphate, has met with little success. When the condition has become well established it has appeared quite evident that the saline treatment is all but useless.

Ipecacuanha. - The much-credited ipecacuanha cure, in the forms of simple powder, ipecacuanha "sine emetine" or Dover's powder, used"in cases of many degrees of severity also proved disappointing. The failure was perhaps for the same reason, that is, the disease was not encountered in its earliest stage.

Monsonia Ovata. - The tincture of "Monsonia ovata," the South African plant which Dr. John Maberley considered almost a specific for dysentery, appeared to produce no effects whatever except nausea and depression.

Perchloride of Mercury, Bismuth, and Opium.-Greater success attended the use of mercury perchloride in mixture with bismuth and opium, and several of our cases which recoveced undoubtedly owe much to this combination.

Bismuth, Chlorodyme, and Izal.-Dr. G. R. K. Crossland, who is one of our civilian medical officers, suggested the use of "izal" in 5-minim doses, and this preparation certainly produced amelioration of symptoms. For my own part, after so many disappointments, I have been much gratified to find that izal combined with bismuth and chlorodyne gives a most satisfactory result. The formula which I am using is $\mathrm{R}$ "Izal" miij, bismuthi subnitratis gr. $\mathbf{x}$, tincturæ chloroformi et morphini m viij, macilaginis acaciæ ad $\xi j$. TTo be taken every two, four, or eight hours, according to the severity of the symptoms. In the few sporadic cases of dysentery which have arisen in our hospital, this combination of drugs has in every case brought about a rapid cure, and in those well-advanced cases of a severe type which have come under our care the results of its use have been equally gratifying.

Diet. - The fact that milk was not a suitable diet for dysentery patients was pointed out to us by Dr. Campbell, the medical officer with the Durban Light Infantry when that regiment was our near and hospitable neighbour. This observation we speedily confirmed both clinically and after death. In several post-mortem examinations of cases of dysentery, as well as in some of enteric fever, made during the earlier part of the campaign, clots of bile-stained casein, the residue of milk diet, were discovered as far down as the third portion of the rectum. My own cases, even those of a severe type, have been given a fairly generous diet. Beef-tea and bread with butter satisfy, and leave a residue which appears to cause but little colic or rectal irritation.

Risks of Enemata.-Our post-mortem observations brought other facts home to us. Great risk must frequently accompany the giving of rectal injections, especially when combined with abdominal massage. Clinically I have found antiseptic enemata and rectal irrigations, even when speedily followed by opiates, to be productive of great distress and no proportionate benefit. After death we have often found the walls of the cæcum, colon, and even rectum so eroded and softened that gentlest manipulation produced laceration or broke down the very feeble adhesions at the sites of impending perforations. I cannot think that liquid introduced into the rectal 
or sigmoid gut can be made to reach the cæcum except by the aid of very violent massage.

Co-existence of Enterie Fever and Dysentery.-The co-existence of enteric fever with dysentery was more than once unexpectedly disclosed in our mortuary tent, and I am permitted to state that the medical returns of the hospital will show how very often the two diseases occur, if not simultaneously, within a short interval of one another. When coexistent the cardinal symptoms of either are certainly much modified, and it is in these cases especially that Widal's reaction has been of the greatest service to us.

\section{NOTES ON A CASE OF ACUTE YELLOW ATROPHY OF THE LIVER.}

BY G. H. PEARCE, L.R.C.P., L.R.C.S.EDIN., L.F.P.S.GLAS., Medical Officer and Public Vaccinator, Darton District Barnsley Union; Medical Officer of Health, Darton.

I HAVE been led to offer these few notes of an extremely interesting case, partly on account of its comparative rarity, the disease usually being seen in pregnant women, and also because it occurred in a man living under very healthy conditions, who spent a very active life, mostly in the fresh air. I saw him frequently before he was taken ill, the last time being a week before when he was out walking.

On the morning of June $16 \mathrm{th}$, 1900, I was sent for to see the patient, who was a farmer 33 years of age. His fa mily history was good, and as far as I could ascertain he had never had any illness with the exception of a cold occasionally. He informed me that his brother, two years younger, used to suffer from "the liver," but he had been all right for some years. The patient's wife told me that her husband had complained of feeling tired and exhausted for several days, and had frequently had to come in to rest whilst pursuing his ordinary avocation on his farm. Two days before calling me in he took to his bed, thinking he would be all right with day's rest, but getting worse they became alarmed, and decided to call in medical aid.

The temperature was $102^{\circ}$; the tongue was dry and baked, reminding one almost of the appearance in some cases of enteric fever; his eyes were glassy and his face slightly flushed; he complained of slight headache and sleeplessness he also said his throat felt sore. but on looking into it $I$ found very little to account for it. His pulse was 105, but of good tone. The heart was slightly displaced downwards and outwards, and there was a suspicion of a slight murmur at the apex. His lungs were congested at the bases, his respirations numbering 25 ; he bad no cough or expectoration. His abdomen was swollen and tympanitic. The area of hepatic dulness was almost entirely gone, and he had great pain on pressure over both the liver and spleen. The tenderness over the liver got better in two days, but worse over the spleen. He had not vomited, but the bowels had moved naturally. His water contained a trace of albumen, and was highly coloured we wished for no food, but was very thirsty. He complained of a good deal of pain in the muscles of his legs.

The next day he felt somewhat better, and his temperature and pulse were $100^{\circ}$ and 90 respectively; the respirations had also fallen to 20. He passed a fairly good day, but got restless towards night.

The next day he was much the same, but the temperature and pulse were lower.

On July 19th his pulse, temperature. and respirations were quite normal. He, however, could not rest anywhere in the bed, had had a sleepless night, and was slightly jaundiced; he had also vomited several times. His bowels had moved every day, but the motions had gradually got lighter in colour; his urine was also much darker and responded to the test for bile.

On June 2oth I was called at 7 A.M., and found him suffering from a violent hæmorrhage from the nose, which had only been going on for about twenty minutes, but during that time he had lost a great quantity of blood. His skin was intensely jaundiced, and numerous small hæmorrhages had occurred under the skin all over his body. He vomited several times during the day, but there was nothing special in its character.
The nose was plugged both anteriorly and posteriorly, but the bleeding continued to a smaller extent the whole day.

On June 2 ist he was much worse, with continued vomiting. Both vomit and motions contained blood. The epistaxis continued the whole day in spite of everything that was done, but towards evening it abated, and finally ceased during the night. The jaundice was intense. The urine contained a large amount of albumen. There was great tenderness over the spleen. The abdomen was not distended. The temperature was quite normal, but his respirations were quicker, there being a good deal of congestion about the bases of the lungs.

On June 22nd he seemed a little better, and said he felt so, but towards night he commenced to ramble, and a man had to sit with him the whole night through, as he wanted to get out of the window, and had several times to be restrained.

He was quite sensible on June $23 \mathrm{rd}$, but was getting perceptibly weaker. I saw him four times that day, the last time in consultation with Dr. Horne, of Barnsles, who concurred in the diagnosis. The patient sank rapidly, and in the afternoon be was speaking to his brother when he suddenly fell back dead. He was quite sensible up to the end. I tried hard to get the relations to allow me to have a small piece of the liver in order to have it examined microscopically, but all my attempts were unavailing. I may add that whatever treatment was resorted to was entirely useless, the case gradually progressing to a fatal termination.

\section{A CASE OF ACUTE YELLOW ATROPHY OF THE LIVER.}

By C. T. ANDERSON, M.R.C.S., L R.C.P.,

Resident Medical Officer, Somerset Hospital, Capetown, South Africa.

THIs is the first case of acute yellow atropby which bas occurred in Somerset Hospital, and, as far as I can ascertain, in Capetown. The case was by no means typical, and the diagnosis was only arrived at four days before death.

A. E. M., aged 22, was one of the senior nurses at Somerset Hospital She was a talr, healthy, active girl, and had never been ill before. She was supposed to have had some mental worry, Lut it was not serious. Hev character was irreproachable.

\section{History of Illness.}

She returned to the hospital from her annual holiday in the early part of Januarr. 1808 . looking as well as usual, but told another nurse that she had slightly hurt her side some days previously, how or to what extent was never discovered. A week later, on January $13^{\text {th }}$, she was noticed II) be quieter than usual, and complained of a headache, but she continued on duty without saying anything more about it. On January r6th she took a pil. col. et hyosc., which acted on the follewing day, but later in the day she complained of indigestion. On January isth she was worse and was sent to bed. In the evening she complained of a constant feeling of sickness. with but little vomiting; bismuth and morphine gave no relief. On January sgth, besides the constant retching, she complained of great pain and tenderness all over the abdomen, which was very rigid. On January 20 th she was distinctly worse; the vomiting 作 astrium. On percussion it was noticed that there was a marked diminution in the area of liver dulness. After two days constipation. castor oil and several enemata proved all but ineffectual. A vaginai examination cast no light on the subject, although perimetritis was suspected at this stage. The urine on this day became slightly bile stained, and in the evening the patient became mildly delirious. Morphine was. njected, but it caused little relief. On January 23 rd the urine was found o be very dark indeed, almost black, and it continued very dark to the end. It was found to contain the bile pigment, and salts and a great. number of leucin plates, but no albumen, blood, or pus. The specific gravity was ro28.

The patient continued in much the same condition for the next two days, the chief trouble being the constipation. On January 24 th a double: oil and soap enema was followed by a large normal stool, and very soon after the patient seemed much better and brighter, the temperature which had never been high, fell to normal, the pulse was good, and the pain left her.

On January 26 th marked cerebral symptoms supervened. There was a feeling of weakness in both legs, which gradually increased to numbness and almost anæsthesia. On January 28 th the numbness had spread to the hands, and the patient began to wander in her speech. Tenderness was now quite limited to the area in front of the liver, and the area of liver dulness was still diminished, although not so markedly as a week previously. The diagnosis of acute yellow atrophy was now made. The cerebral symptoms became more marked and paralysis came on. The lucid intervals became skorter and her speech thicker. Her friends saw her on Monday, February ist, and were recognised, but she became comatose on Tuesday afternoon, and she died in the evening.

\section{Necropsy.}

Naked-eye Appearances. - The necropsy was made twenty hours after death. Verv little wasting was found, and there was no distension of the abdomen. The mesentery was very yellow, and the whole of the peri- 